\title{
URANIUM ATTENUATED BY A WETLAND 50 YEARS AFTER RELEASE
}

\section{INTO A STREAM}

Daniel I. Kaplan ${ }^{a^{*}}$, Ronald Smith ${ }^{\mathrm{b}}$, Connor J. Parker ${ }^{\mathrm{c}}$, Matthew Baker ${ }^{\mathrm{d}}$, Tristan Cabrerac, Brennan O. Ferguson ${ }^{\mathrm{c}}$, Kenneth M. Kemner ${ }^{\mathrm{e}}$, Michael Laird ${ }^{\mathrm{a}}$, Christina Logand ${ }^{\mathrm{d}}$, Jeffry Lott ${ }^{\mathrm{d}}$, Lisa

Manglass $^{c}$, Nicole E. Martinez ${ }^{c}$, Dawn Montgomery ${ }^{c}$, John C. Seaman ${ }^{\mathrm{d}}$, Morgan Shapiro ${ }^{\mathrm{d}}$, and Brian A. Powella,c

a Savannah River National Laboratory, Aiken, SC USA

${ }^{\mathrm{b}}$ Savannah River Nuclear Solutions, Aiken, SC USA

${ }^{\mathrm{c}}$ Department of Environmental Engineering and Earth Science, Clemson University, Clemson,

$13{ }^{\mathrm{c}}$ Departm

15 d Savannah River Ecology Laboratory, University of Georgia, Aiken, SC USA

e Argonne National Laboratory, Argonne, IL USA

* Corresponding author, daniel.kaplan@srnl.doe.gov

The supplemental information for this manuscript includes:

- 5 pages

- 3 figures, and

- 1 background information section entitled, "Waste Generated from the SRS Fuel Fabrication Facility."

1. Figure S1. Historical uranium releases to streams from the Savannah River Site's Fuel Fabrication Facility (data provided in Evans et al. 1992).

2. Figure S2. Expanded map of uranium activity in Tim's Branch, including 291,000 gamma spectra acquisitions (1 second per measurement).

3. Figure S3. Images taken during gamma survey. (Left) Surveyor carrying computer tablet and $7.3 \mathrm{~kg}$ backpack equipped with a NaI detector, control module (multi-channel analyzer) and GPS system. (Right) A screenshot of the computer tablet showing the real-time position of the surveyor (black icon), survey transect lines (green lines), satellite image of terrain, and map of total gamma emissions prior of each 1-second acquisition (dots with colors corresponding to intensity of detected gamma emissions). Screenshot taken while surveying the A-14 Delta.

4. Section: Waste Generated from the SRS Fuel Fabrication Facility 


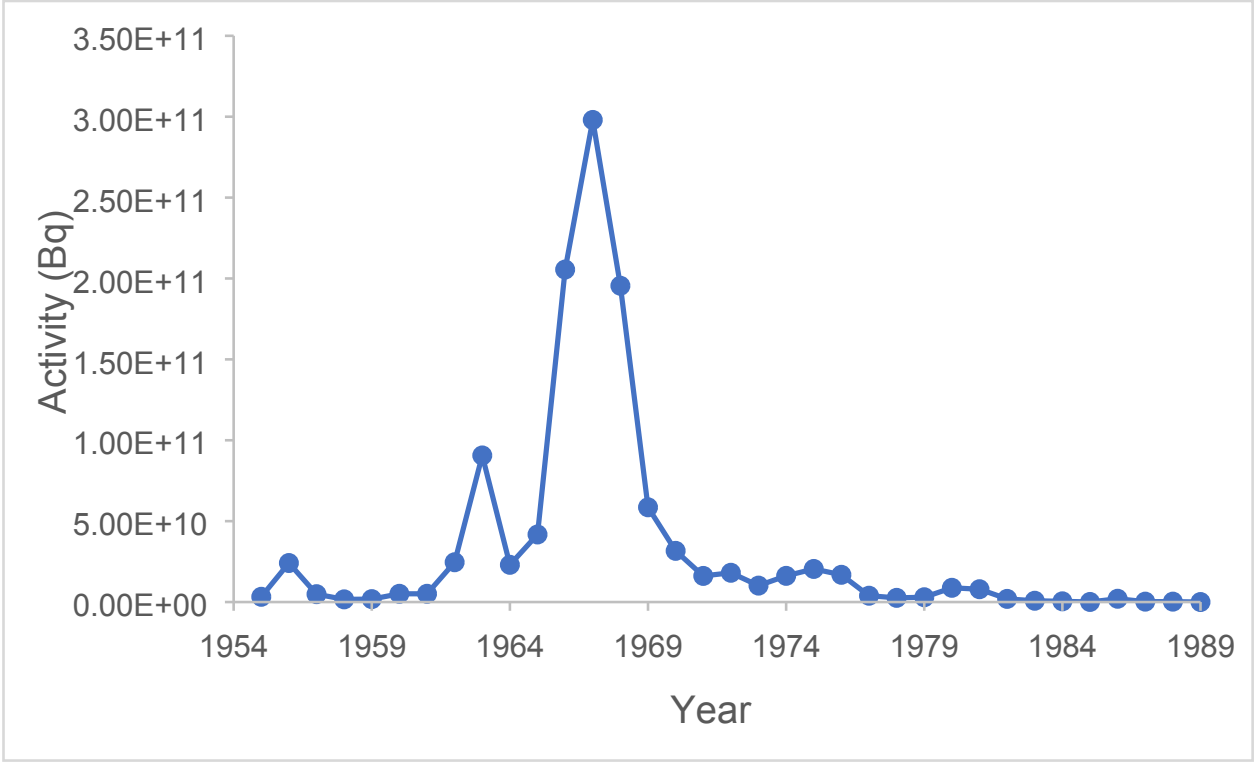

42 Figure S1. Historical uranium releases to streams from the Savannah River Site's Fuel 43 Fabrication Facility (data provided in Evans et al. ${ }^{1}$ ).

44

45 


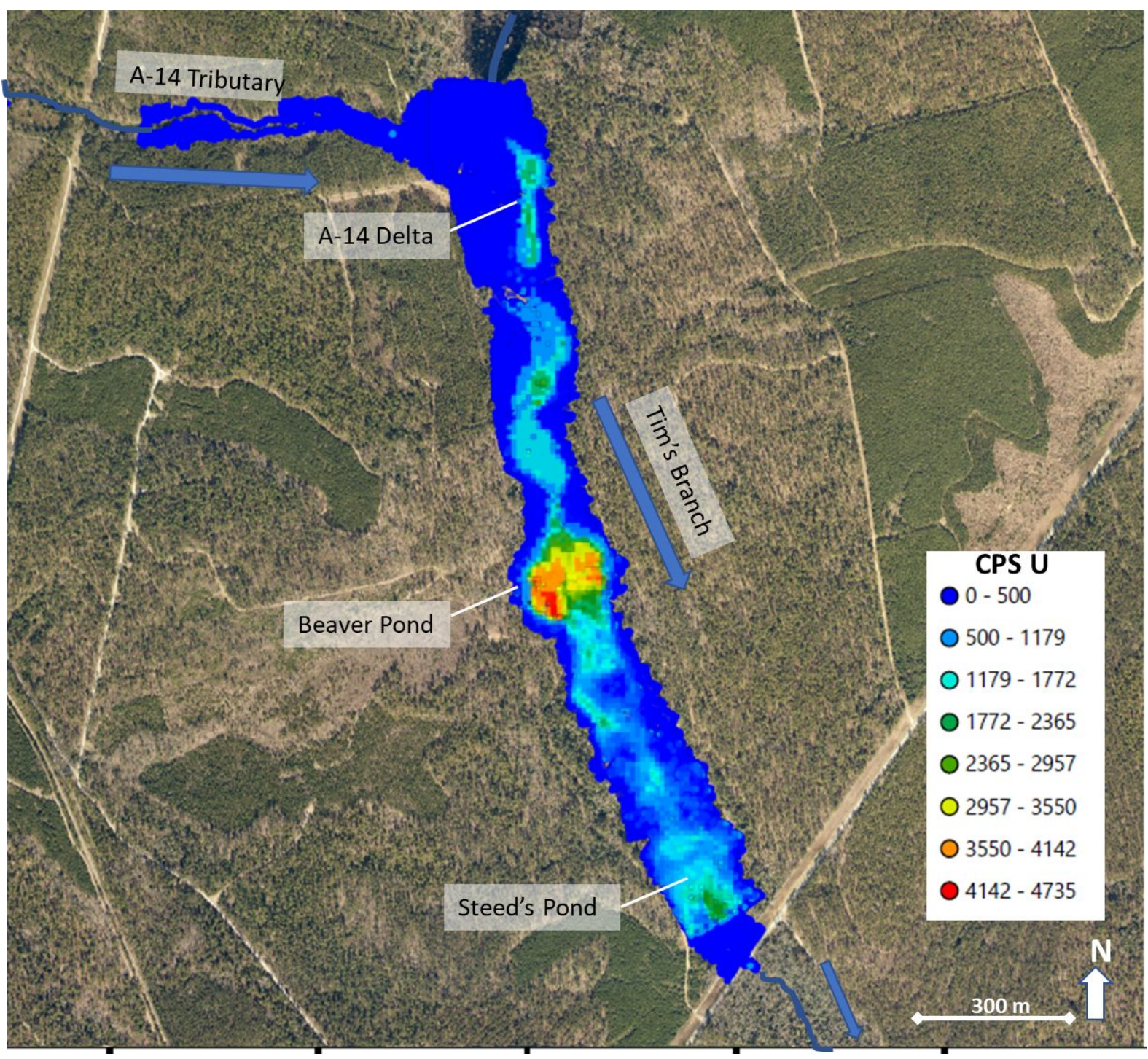

Figure S2. Expanded map of uranium activity in Tim's Branch, including 291,000 gamma 48 spectra acquisitions (1 second per measurement). 


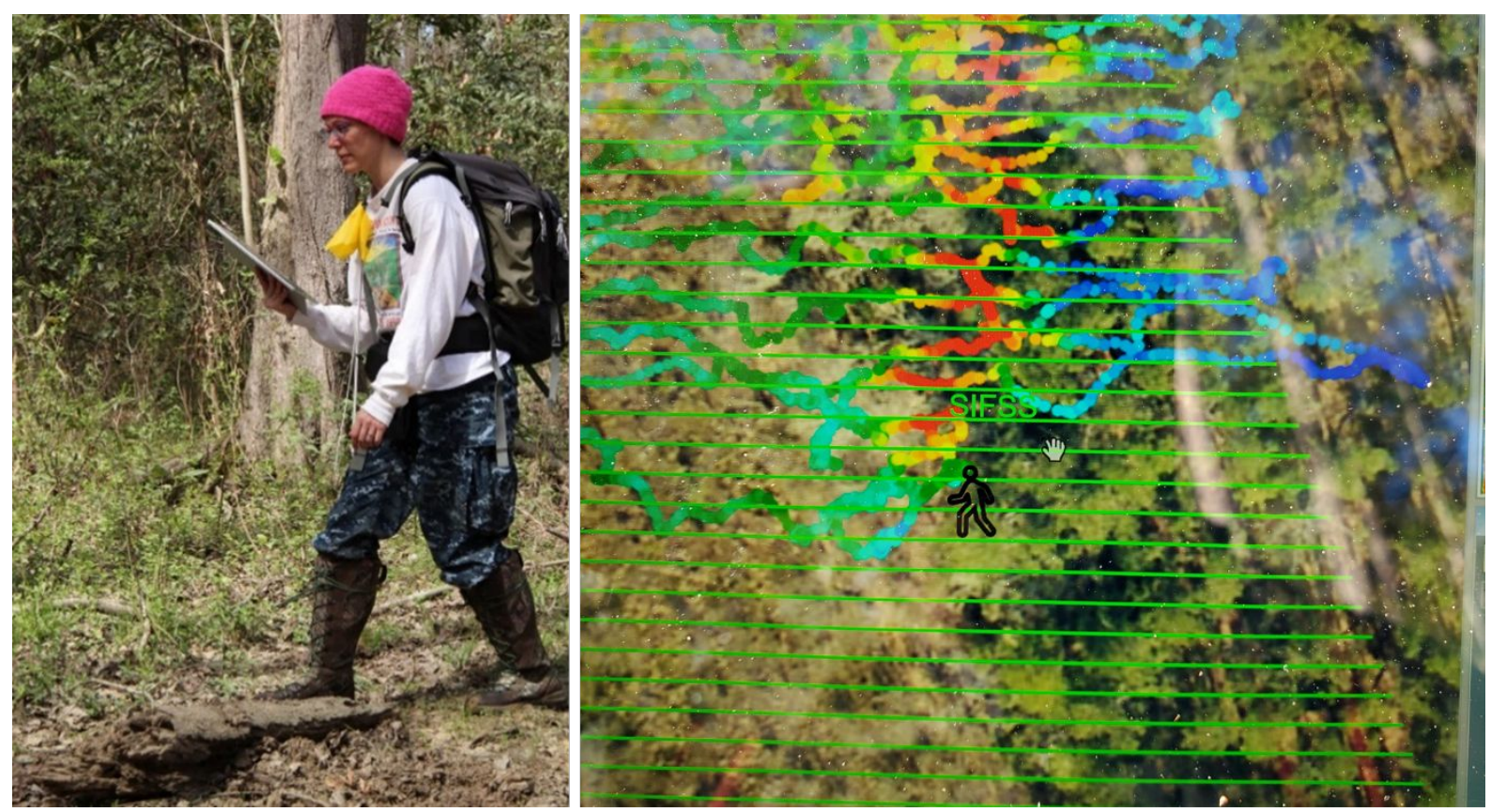

Figure S3. Images taken during gamma survey. (Left) Surveyor carrying computer tablet and $7.3 \mathrm{~kg}$ backpack equipped with a NaI detector, control module (multi-channel analyzer) and GPS system. (Right) A screen shot taken of the computer tablet showing the real-time position of the surveyor (black icon), survey transect lines (green lines), satellite image of terrain, and map of total gamma emissions prior of each 1-second acquisition (dots with colors corresponding to intensity of detected gamma emissions). Screenshot taken while surveying 50 the A-14 Delta. (Photographs from D. Kaplan with permission) 


\section{Description of Generation of Waste from the SRS Fuel Fabrication Facility}

The Fuel Fabrication Facility on the Savannah River Site in South Carolina made U fuel and target assemblies for use in the production of nuclear materials used for defense purposes, including ${ }^{238} \mathrm{Pu}$ and ${ }^{239} \mathrm{Pu} .{ }^{1}$ The mission at the facility changed during the time of operation, 1965 to 1988, influencing the form that $U$ may have been released into the environment. Various missions involved working with natural $U$, low enriched $U$, and highly enriched $U$ for fuel and target manufacturing, and depleted $U$ for fuel. The fuels and targets were composed of $U$ metal, $\mathrm{U}(0)$, that were cladded with $\mathrm{Al}$ at the Fuel Fabrication Facility.

Uranium waste was generated at several steps during this process, including acid etching (nitric, phosphoric, and sulfuric), cutting, milling, and chlorinated solvent washing. Colloidal material was generated during a quality control autoclaving step to test the bond between the $U$ and the Al casing. Approximately $95 \%$ of the targets/fuels failed this test, resulting in the formation of visible white powder at the failed bonding locations, presumably a U(IV) oxide or mix oxides $\left(\mathrm{U}_{4} \mathrm{O}_{9}\right.$, and $\left.\mathrm{U}_{3} \mathrm{O}_{8}\right)$. Waste from the facility, reported at concentrations of $300 \mathrm{~g} / \mathrm{L} \mathrm{U},{ }^{2}$ was treated with hydroxide to promote precipitation and then passed through a settling basin and a filtration system before releasing to a stream, the A14 Tributary and later to an unlined settling basin. A total of $43,500 \mathrm{~kg}$ of $U$ was released to the environment, of which, approximately $61 \%$ of the U was released during a 3-year period, 1968 to 1971 (Supplemental Information, Figure $\mathrm{S} 1){ }^{2}$ During this period, the facility was using depleted $U$ (possessing a low ${ }^{235} \mathrm{U} /{ }^{238} \mathrm{U}$ ratio) to make targets. ${ }^{1}$ In summary, based on historic records of the facility practices and quantities of waste released, and in the absence of waste characterization data, it appears that the U released into the A-14 Tributary and the settling basin was in a dissolved, colloidal and particulate form, was primarily depleted $U$, and may have included $U$ in the $0,4,6$, and possibly 5 oxidation states. The U colloids and particulates may have included U bound to clay particles, metallic fines, and waste process precipitates (perhaps including sodium urinate, hydrogen uranyl phosphate, uranium oxide and uranium mixed oxides).

\section{References}

1. Reed, M.B. and M.T. Swanson, 300/M-Area-Fuel and Target Fabrication. 2006, New South Associates: Stone Mountain, GA.

2. Evans, A.G., et al., Uranium in the Savannah River Site Environment. 1992: Westinghouse Savannah River Company, Aiken, SC. 